\title{
Why does household demand for shares decline during the crisis? The French case
}

\author{
Luc Arrondel* and André Masson**
}

\begin{abstract}
The economic crisis has impacted French savers, now less willing to take risks in their financial decisions. What is the explanation behind these changes? According to "standard" theory, savers' investments rest on three fundamental determinants: present resources; expected risk and returns on assets, as well as expectations on earned income; and lastly, individual preferences, especially risk preferences. We use French data from the Pater panel, a survey collected in 2007 and again in 2009, 2011 and 2014. We show that it is the downward adjustment in the expected return from shares and negative impacts on current resources that help explain why the French are investing less and less in risky assets. Risk preferences, however, have remained stable. In contrast, the resurgence in optimism shown by savers in 2014 did not play out in reality, as the number of shareholders has continued to decrease. A new puzzle to be solved?
\end{abstract}

JEL Classification: J12, D63, D31, D12

Keywords: saver preferences, risk aversion, time preference, wealth, demand for stocks

Reminder:

The opinions and analyses in this article

are those of the author(s)

and do not

necessarily reflect

their institution's

or Insee's views.

* CNRS-Paris School of Economics (arrondel@pse.ens.fr).

${ }^{* *}$ CNRS-Paris School of Economics and EHESS (amasson@pse.ens.fr).

Acknowledgements - The last wave of the Pater survey in 2014 would not have been possible without the financial contribution of Cepremap and Fondation Médéric-Alzheimer, as well as that of the Autorité des Marchés Financiers, Institut pour la Recherche at Caisse des Dépôts et Consignations and the firm Harvest. This research was also supported by a grant jointly provided by the Chair in "Private Investors in the face of Risk: Analysis and Market Response" (Fondation du Risque, Université Paris-Dauphine, ENSAE, Groupama), the Europlace Institute of Finance (EIF) and the ANR project 11-LabX-0019. Hector Calvo-Pardo guidance on measuring expectations has been of crucial importance. We also wish to thank, for their remarks and comments, participants in the "Economics and Psychology Seminar" (Paris-I, 29/01/2016), CREM (Rennes, 07/05/2016), "Behaviour" (PSE, 29/09/2016), and "Retirement and Ageing" (CdC, 11/10/2016) seminars, and in the conference on "Financial inclusion, portfolio choice, and household saving in China and beyond", (University of Birmingham, 3-4 November 2016). Comments from two anonymous rapporteurs helped us improve the final text. 
G reat Recession savers underwent multiple "depressions": a financial and economic crisis making the environment more uncertain; concerns for the future of the social protection system (pensions, health insurance, etc.), rising unemployment risks, the vagueness of fiscal and institutional reform, enthusiasm for "activation" policies aimed at making individuals responsible for their futures, etc. Probably as a result of all the aforementioned uncertainties, French savers favour safe investments and short-term assets now even more than in the past, in particular passbook savings, insurance savings and real estate, at the expense of risky, long-term financial investments. For instance, according to the French Wealth survey (Insee's survey Patrimoine) the proportion of shares holders fell from approximately one in 4 French households in 2004 to one in 6 in 2014 (and one in 5 in 2010).

These figures reveal a significant drop in the number of shareholding households during the financial crisis, as well as, more generally speaking, the structurally-low participation rate in the stock market. This lack of interest on the part of savers for the securities market gives rise to two puzzles: the stock participation puzzle and the equity premium puzzle, despite better long-term returns to equities. These puzzles, beyond the case of France, reflect a widespread phenomenon, in particular in the euro zone. Indeed, according to the HFCS (Household Finance and Consumption Survey), approximately one in five households own risky financial assets in major countries and the overall euro zone (Arrondel et al., 2016). Risky assets ownership is higher, but still far from $100 \%$, among the wealthiest households: for instance, in the wealthiest $5 \%$, nearly three out of four households in Belgium hold such assets, as compared to just under two out of three in France, and around one out of two in Spain, Italy and Germany (Arrondel \& Masson, 2015).

Faced with these two empirical puzzles, economists offer a variety of explanations in the framework of standard theory enlarged to a more realistic environment that acknowledges, in particular, that the markets are imperfect, as well as in the framework of behavioural economics, which fundamentally calls the standard model into question, in particular the rationality of the saver. Both behavioural finance and the standard framework make savers' behaviours and portfolio decisions dependent on only three sets of individual determinants: preferences (risk aversion, time preference, etc.); current resources, which can show varying levels of risk or availability; and expectations on future resources or tastes, in particular on equity return and risk and earned income. The question then becomes identifying "what has changed" since the collapse of Lehman Brothers in 2008, and the sovereign debt crisis in 2011: more specifically, has the "psyche" of savers changed (has their risk aversion risen), or is it rather that their expectations on asset return have significantly adjusted downward, in an environment generating high anxiety? In contrast, behaviourist models acknowledge non-standard forms of rationality and bring in other determinants of savings behaviour than mere risk aversion, in particular aversion to loss and to ambiguity.

Today's crisis provides valuable insights into households' financial behaviours in situations of high uncertainty. It entails to profoundly rethink assumptions regarding household finance in general and the formation of beliefs or expectations in particular. The first section will offer an overview of the current debate on the basic premises of stable preferences and rational expectations, which are assumed to respond only to "innovation": standard theory commonly recognises both these premises, while psychological economics, to the contrary, posits that changes in individuals' tastes can result from emotions and that expectations can fluctuate wildly. Today's financial and economic crisis also offers an ideal observatory, a kind of "natural" experiment of sorts, which sheds light on and magnifies the obstacles to household demand for shares, as long as fine-grained micro-economic data are available and make it possible to track the (same) savers prior to and during this troubled period. The longitudinal data from Pater surveys, unique in France, offer us the means to study the responses of savers during the Great Recession, and identify the changes that could explain their heightened cautiousness, by observing the concurrent development of their resources, preferences and increasingly pessimistic expectations. This analysis is developed in the second part of the article.

\section{Why do households hold so few shares and how can changes in their behaviour be explained?}

The risk premium puzzle was born of the inability of standard savings theory, a model that combines the life cycle hypothesis with the 
theory of optimal portfolio choices (Merton, 1971), to explain households' low investment in shares. In attempting to solve this puzzle, economists have fallen into one of two categories: on one side, they expand the base model to a more realistic environment, allowing in particular for the existence of transaction costs, market imperfections and market incompleteness; on the other, in the framework of behavioural economics, they fundamentally challenge the assumed rationality of the standard theory's saver, both in terms of choices and expectation. After a brief review of the theory (see a more extensive presentation in online Complement C1), we will look at how the crisis also offers a valuable contribution to the critical discussion between "standard" economy advocates and those of psychological economy to explain the behaviours of households in the face of financial risk-taking.

\section{From the "standard" investor to the non-standard investor: a brief theoretical review}

The standard approach to saving behaviour primarily combines Arrow's theory on optimal portfolios (1965) with Modigliani's life cycle model (1986). In the simplest version, where the investor has the choice between a risky asset (which can match up with the market portfolio risk) with expected return $\alpha$ and standard deviation $\sigma, r$ a risk-free asset; $p$ the proportion of risky assets in the total assets depends on the "risk premium" $(\alpha-r)$, the volatility of the risky asset $(\sigma)$ and the individual's relative risk aversion $(\gamma)$, such that (for an isoelastic utility):

$$
p=(\alpha-r) / \sigma^{2} \gamma
$$

The characteristics of assets $(\alpha, r, \sigma)$ depend on the saver's financial expectations, which are in turn a function of the degree to which they are informed. As soon as the expectations are uniform, this model thus predicts that it is always optimal for the individual to hold risky assets, if only as a minimal fraction of their total wealth. This baseline model can be enhanced by taking into account market imperfections or incompleteness: transaction and information costs, exposure to other risks (income, human capital, housing, health, etc.) and liquidity constraints. However, even in this extended version, the standard model offers only limited predictive power. It generates portfolios that are much more diversified than those seen in reality. Transaction costs, other risks, liquidity or credit constraints and ban on equity short-selling limit investments made all the more, but do not prevent a minimum amount of shares held from being profitable, as a result of their long-term high return (over 20 years or more).

The limited attractiveness of the stock market is then analysed, in general, as resulting from the existence of fixed entry costs of all kinds, including informational. These (fixed) costs of transaction, ownership and management, and threshold and indivisibility effects are assumed to explain the massive effect of total wealth on its degree of diversification (King \& Leape, 1998); however, if the portfolios composed only of liquidities and quasi-liquidities are the province of the smallest fortunes, while well-diversified portfolios that of the highest, the explanatory power of the wealth level on the number of assets held or their composition is more limited to intermediate-level wealth (see Arrondel \& Masson, 2015, for France). Thus, other factors need to be brought into the picture if we are to understand the low proportion of risky assets in household portfolios: liquidity constraints and other lending impossibilities (Gollier, 2001), risks faced outside financial markets (affecting income, health, family), but also taxation regimes, which can be more attractive with specific types of investments, in particular real estate. In addition to the limits of basic portfolio choice theory, even when extended (Guiso \& Sodini, 2012), a variety of biases affect the way households manage their securities portfolio, calling more largely into question the standard model: a "home" bias in favour of national-level shares, "naive" (uniform) diversification, a "disposition" effect that causes individuals to part too early with winning assets and too late from losing assets, status quo bias, inertia, excessive transactions (Vissing-Jorgensen, 2003), etc.

On the other hand, "non-standard" models call into question the founding assumption of saver's rationality, and introduce preference parameters other than mere risk aversion, in particular aversion to loss and to ambiguity.

In the model developed by Kahneman and Tversky (1979), individuals value gains and losses differently: for those averse to loss, the disutility derived from a loss is greater than the utility derived from an equivalent gain. Barberis et al. (2006) also show that the combination of loss aversion and a focused "narrow framing" of stocks may help to understand non-participation in a stock market, even 
without transaction costs. Aversion to ambiguity, meaning the fact that share return probabilities are not known (uncertain, as defined by Knight), can also explain failure to participate in the stock market (Ellsberg, 1961; Bossaerts et al., 2010; Epstein \& Schneider, 2010) or under-investment in risky assets (Peijnenburg, 2014). ${ }^{1}$ Individuals could also suffer from inadequate financial literacy and limited cognitive abilities (Lusardi, 2009; Guiso \& Sodini, 2012) or could be victim to their emotions (Guiso et al., 2014). They are then said to make "errors" in calculation or strategy, or in expectation, when gathering and processing information -including overconfidence in their own judgements- and thus have trouble planning over the long term.

Despite some progress, both in extended models of the standard approach or those of behavioural economics, the two puzzles formed by stock market participation and equity risk premium have not yet been fully elucidated to date, and none of the above approaches effectively explain why the rate of share ownership has never exceeded one quarter of households these past few years, even in the most favourable periods of economic growth or stock market: neither unfavourable taxation conditions nor off-putting transaction costs can be invoked here, as ownership remains limited in households with large (financial) assets and education level.

One final avenue to explore is that of investors' information: the basic portfolio choice model assumes that financial information is free and available to all investors. Yet a series of stylised facts shows that portfolio diversification and share ownership increase with age (until retirement), as necessary financial information is gained, as well as with the level of general education (Arrondel \& Masson, 2015). This role of education is backed up by a broader habitus effect and, above all, the ownership of transferable securities (as well as life insurance) appears to be inherited, increasing sharply with the presence of the same assets in the parents' wealth. A large body of recent literature looks into the factors relating to information, which appear to play a major part

1. More specifically, ambiguity could also explain the two puzzles connected with portfolio management, home-bias (French \& Poterba, 1991) and own-equity stock (Benartzi, 2001): home bias translates as low demand for foreign shares, the probabilities of which are little known to investors; in contrast, an investor adverse to ambiguity will be likely to give preference to shares issued by the company for which they work, favouring "familiarity" over risk diversification. in determining participation in the stock market: cognitive abilities (Christelis et al., 2010 ; Grinblatt et al., 2011), confidence (Guiso et al., 2008), "sensitivity" to financial matters (Guiso \& Jappelli, 2005), time spent collecting information (Guiso \& Jappelli, 2007), social interactions (Hong et al., 2004), optimism (Jouini et al., 2006), financial education (van Rooij et al., 2011; Lusardi \& Mitchell, 2014). However, the exact mechanism by which these factors influence households' financial decision-making (via the stock of information available, expectations, etc.) has yet to be formally established (Grinblatt et al., 2011). However, there too, these factors even all combined do not adequately explain why direct shareholding is now chosen by no more than one in seven French households.

The crisis has made savers more cautious in their behaviour, pushing them to prefer safe assets, at the expense of risky assets. Analysis of the factors explaining change in behaviours during the crisis is a valuable "test" of the two cornerstones to the standard approach: temporal stability in preferences and the rational expectations hypothesis.

\section{Possible sources of change in behaviour: preferences, resources and expectations}

In the standard approach, portfolio choice theory shows that demand for risky assets (see Equation 1) decreases with the (relative) risk aversion, decreases with exposure to risk on earned income and is an increasing function of the household's expected risk premium, but a decreasing one of the expected risk portfolio. More generally speaking, investment behaviours depend on the interaction between three components:

(i) risk (and time) preferences, inherited from the past;

(ii) disposable resources and present endowments (assets and income, liquidity constraints, current unemployment risk; health and human capital, etc.; financial literacy and cognitive capacities that determine the individual's information level);

(iii) expectations and beliefs with respect to the future: earned income, unemployment probabilities, pension rights, expected return and risk on financial or real estate assets, inflation, credit constraints, etc. 
These three components can be summed up in the following empirical equation:

Behaviours $=F($ Preferences, current Resources,

$$
\text { Expectations) }
$$

To study the increased behavioural cautiousness of French savers on the stock market since the start of the crisis, the relationship (2) needs to be rewritten in differences:

$\Delta$ Behaviours $=F(\Delta$ Preferences, $\Delta$ current Resources

$$
\Delta \text { Expectations) }
$$

Consequently, to explain the changes in financial behaviour during the crisis, the following factors can be suggested: an increase in risk aversion - or aversion to loss and ambiguity, etc. ( $\Delta$ Preferences); reduced and/or riskier resources ( $\Delta$ current Resources); gloomier expectations on the assets' technical characteristics (return, volatility) ( $\Delta$ Expectations).

Empirical analysis of relationship (3) will enable us to test, during the crisis and on French data, two foundations of standard savings theory: the assumption of temporal stability in preferences and the rational expectations hypothesis. Let us first go back over the theoretical challenges raised with this latter hypothesis before coming to the conclusions of foreign studies that offer empirical measurements of risk preferences.

\section{Challenging the rational expectations hypothesis}

The 2008 financial crisis unsettled the macro-economy's traditional foundations to a certain extent (Hall, 2010; Stiglitz, 2011). Debate today revolves around the role of expectations in the standard macro-economic models, in particular on the financial markets. These models are based on the paradigm of rational expectations in which (omniscient) individuals draw on all available information, past and present, to form their expectations, which are consistent with the economic model connecting the expected variable with the other variables. According to these assumptions, individuals, on average, are not mistaken about the future, revise their predictions only in accordance with innovations observed (and not their emotions) and, in fact, share a single, identical prediction. The paradigm of rational expectations leaves but little room for lasting heterogeneity in beliefs.

Challenging the rational expectations hypothesis, in particular belief homogeneity, appears a promising avenue for research. Behavioural finance puts forward, in this sense, different cognitive biases in the formation of expectations; ${ }^{2}$ according to Gollier (2013, p. 3), "it gives people license to dream of impossible returns, reject the information that does not suit them [though relevant], or agree to disagree with one another", these psychological biases being likely to contribute to explaining "bubbles, cycles and crashes", especially if they are reinforced by biased media coverage; it is also concerned by the "extreme pessimism of economic agents during the phases of [acute] crisis" caused by a strong aversion to ambiguity combined with increasingly gloomy expectations on stock market prices. While considering the applications of behavioural economics to finance relatively disappointing to date, Guesnerie (2010, p. 1) develops another avenue for research in order to understand expectations: "What is at stake here is the ability of agents to coordinate their depictions of the future. The optimism of many a financial market model -for instance, those which point to forms of informational market efficiency- relies largely on the optimism of the assumption of coordinated expectations. Whereby the said optimism should be explained and not only assumed."

To assess the heterogeneity of expectations, the best method remains to measure them in surveys as Dominitz and Manski (2011) suggest, and evaluate their impact on financial behaviours (Arrondel et al., 2016). The impact of the 2008 crisis on stock market expectations has been analysed by Hudomiet et al. (2011) for the United States, based on data from the Health and Retirement Survey (HRS, 2008-2009). They show that, on average, the crisis had a (temporary) positive effect on expected return and variance, as well as on expectation heterogeneity (in the longer term) within the American population. More specifically, shareholders form more optimistic, less uncertain and more uniform expectations than do non-shareholders. However, shareholders' expectation heterogeneity has increased relatively after the crisis. The same can be observed even looking at groups of informed persons compared to non-informed persons, or even based on level of cognitive ability (high versus low). The authors

2. "Representativeness" bias in particular causes a (positive) combination of circumstances to be seen too positively even when it may be the result of chance, or cause initial expectations to be inadequately adjusted in light of realities (Kahnemann, 2011). "Availability" bias, which causes individuals to place too much value on personal events or events connected to their own experience, and "anchoring" basis, were concepts ushered in by Tversky and Kahneman (1974), etc. 
conclude that different categories of population do not receive the same signals or do not respond to them in the same manner, thus lending credence to the heterogeneity hypothesis as regards households' financial expectations.

\section{Time stability of preferences with regard to the risk in question}

The time stability of preferences hypothesis is implicitly at the heart of standard saver theory. In most models, preferences are assumed to be exogenous and constant over time. As Stigler and Becker (1977) wrote in a hallmark article, individuals' preferences do not change and changing behaviours can come only from changes in the economic environment.

This taste invariance hypothesis has been challenged by abundant empirical literature based on survey data or experimental protocols. This research is aimed at testing whether individuals' preferences evolve over time, or whether they are modified for the long term by life events (health problems, death of loved ones, unemployment, financial losses, etc.) and structural shocks (natural disasters, wars, economic crises, etc.) which individuals have to face. ${ }^{3}$ Many articles address in particular the connection between the economic environment and attitudes towards risk, in particular during times of crisis. Sahm (2012) for instance, studies change in risk aversion based on responses to a lottery regarding professional choices over the 1992-2002 period in the United States (resulting from different waves of the HRS panel). Her analysis on individual panel data shows that nearly three-fourths of the variation in risk aversion can be explained by permanent individual heterogeneity, age and macroeconomic environment explaining the remainder. This study thus tends to assert preferences stability, but over a relatively quiet pre-crisis period. Other recent work following the same savers during the crisis show more contrasting results. Guiso et al. (2014) use data on investments made by an Italian bank's customers before and after the 2008 financial crisis. They measure individuals' risk aversion using a qualitative question on the propensity to invest in risky assets, first, $(c f$.

3. Chuang and Schechter (2015) survey the studies considering the impact of natural disasters and wars on individual preferences (aversion to risk, preference for the present). The result is a contrasting picture, whether in terms of tolerance for risk or time preference: some studies show an increase in risk aversion and impatience due to shocks, while others point up a decrease! Chanel et al. (2014) show for instance that Danish soldiers on mission in Afghanistan in Spring 2011 had, on average, become less risk-averse and more impatient after combat. infra, Figure II) and based on a series of lotteries, as in experimental economics, secondly. They show that risk aversion increased after the financial crisis, even for those who did not undergo any financial losses. According to the authors, an emotion, the "fear" triggered by the crisis, is the reason for this outcome. ${ }^{4}$

Cohn et al. (2015), similarly, demonstrate the counter-cyclical nature of risk aversion (individuals are more risk tolerant when markets are booming and vice versa) on the basis of a lab experiment carried out with traders. Drawing upon methods derived from psychometrics, the subjects are "conditioned" to behave either during "boom" or during "bust" periods. Their experience shows that traders conditioned during "bust" periods are less inclined to take financial risks than are their counterparts conditioned during "boom" periods. Like Guiso et al. (2014), they show that fear could be the reason behind this outcome.

Dohmen et al. (2016) use data from Germany's Socio-Economic Panel and the Ukrainian Longitudinal Monitoring Survey to analyse time stability in risk aversion measured by a Likert scale ( 0 to 10 ) over the 2007-2012 period. They also observe that in both countries, individuals appear less risk tolerant after 2008 than before the crisis. The change is said to be due primarily to the macro-economic shocks triggered by the crisis, while the actual experience of the individuals and their labour market status is said to play only a minor role. Using other data from Germany (SAVE), Necket and Ziegelmeyer (2016) show that households that ascribe their loss of wealth to the crisis are also less risk tolerant (as measured on the Likert scale).

The results from Weber et al. (2012) go against the conclusions of these previous studies. Drawing upon data on customers of a British bank, they show that demand for risky assets significantly declined between September 2008 and June 2009. This change is not, however, due to a variation in the customers' risk aversion (still measured with the same scale), which remained stable over the same period, but to changes in their individual expectations regarding return and risk on equities. Malmendier and Nagel (2011) adopt a longer-term vision of the

4. To test this hypothesis, they doubled up their study with: a "randomised" laboratory experiment on two samples, one involving individuals who had been shown a horror film (The Hostel) before answering the lottery, the other individuals who had not watched any film. The authors concluded, controlling individuals by their taste in films, that those who were still under the impact of the horror film proved less tolerant with respect to risk. 
impact of macro-economic shocks on attitudes toward risk in the financial arena. Using data from the US Survey of Consumer Finances over the 1960-2007 period, they show that people who have, in particular in early childhood, experienced periods of low-return securities (particularly during the "Great Depression" in the aftermath of the 1929 crisis) take less risk in their subsequent investment decisions (see question in Figure II). Their expectations on future returns are also more pessimistic than those of individuals who have experienced periods of high return; it is also likely that they are less tolerant with regard to risk. These effects taper off, however, with time.

Although no final conclusions can be drawn, empirical results appear to lean, by and large, toward an increase of risk aversion on the part of savers during the crisis or periods of recession, the said increase perhaps explaining in part the drop in their risky investments. Two criticisms can be voiced nonetheless with respect to the studies in question - regardless of whether they confirm preference stability. The first reservation is methodological in nature and pertains to risk aversion measures (Arrondel \& Masson, 2014), some of which relate more to risk-taking behaviours (a propensity to take risks) than to intrinsic preferences (as with the question in Figure II). But above all, the most common measures derived from lotteries on professional choices or Likert scales show significant flaws, to which we will return later. The second criticism, in particular against Dohmen et al., 2016, is econometric: conclusions based on panel data (fixed effects models) need to be taken with care, as they do not always make it possible to separate age effects (risk aversion increasing over the life cycle) from period effects.

\section{The French savers during the Great Recession}

We will now study changes in individual preferences, revisions to subjective expectations on return and equity risk and the impact of the crisis on available resources, then connect those potential changes up with those observed on investment behaviours, in particular demand for shares. In other words, we seek to empirically estimate a type (3) relationship. To do so, we will turn to the Pater surveys (French surveys on Household Wealth, Time and Risk Preferences -see Box 1), which offers the probably unique advantage of combining all the information needed for such an estimation over a representative sample of the French population. Thanks to its longitudinal dimension and the subjective information gathered, this survey makes it possible to study the consequences of the crisis on French savers' financial behaviours, their preferences when it comes to saving, their resources, and their expectations about the labour market and assets.

Compared to the studies presented earlier on risk preferences time stability, the originality of our empirical approach lies in the variety of measures of preference used: beside the usual risk aversion measures used in these studies, we will adopt, to avoid the flaws of these measures, a new approach based on a "scoring" procedure. It results in more satisfying measures of preference and thus enables a more robust test of the time stability of risk tolerance. In addition, the dates of each wave of the Pater panel study were particularly well-chosen: May 2007 coincides with high CAC 40 indices, while the two following waves (June 2009 and November 2011) come shortly after major crashes of this same market (see figure in Box 1); these historical breaks will help us separate age effects from period effects in the explanation of changes in preferences.

\section{Financial behaviours became less and less risky during the crisis...}

The data from the Insee's Wealth surveys (surveys Patrimoine) show that the percentage of shareholders (excluding mutual funds) fell by seven points in France, from 19\% of households in 2004 to $12 \%$ in 2014 (15\% in 2010). According to the quarterly survey SoFia carried out by Tns-Sofres with 12,000 panel members (including those of our Pater surveys), the number of "direct" individual shareholders decreased by $55 \%$ following the collapse of Lehman Brothers, between December 2008 and March 2016 (13.8\% to 6.2\%). These data show an increase of around $30 \%$ in the amounts placed on "Livret A" savings passbooks over the same period. This decrease in the number of shareholding households (direct or indirect) also emerges from the Pater surveys (Figure I). Over the period from 2007-2014, the percentage of households holding shares in all households decreased from $31.1 \%$ to $16.8 \%$ ( $-46 \%)$. The decrease can also be seen in the balanced panel, which includes 807 households across 


\section{Box 1 - The French survey on Household Wealth, Time and Risk Preferences (Pater) 2007-2009-2011-2014}

The Pater survey was initiated in 2002, in order to supplement Insee's Household Wealth surveys on more subjective aspects (preferences, expectations, attitudes). The panel waves were structured on our initiative and conducted by the TNS-Sofres Institute (see Arrondel \& Masson, 2014). The surveys' history is summarised below.

The strong panel-based dimension and the timing of the waves (May 2007, June 2009, November 2011 and December 2014) made it possible to cover a period of significant stock market variations, before and after the Lehman Brothers collapse in 2008, and after the August 2011 sovereign debt crisis (see Figure).

In addition to the information usually collected in Insee's Wealth surveys, Pater surveys include a range of qualitative and subjective questions aimed at measuring individuals' preferences as regards savings, as well as their expectations with regards to their future resources (Table B).

Table A

Pater survey waves

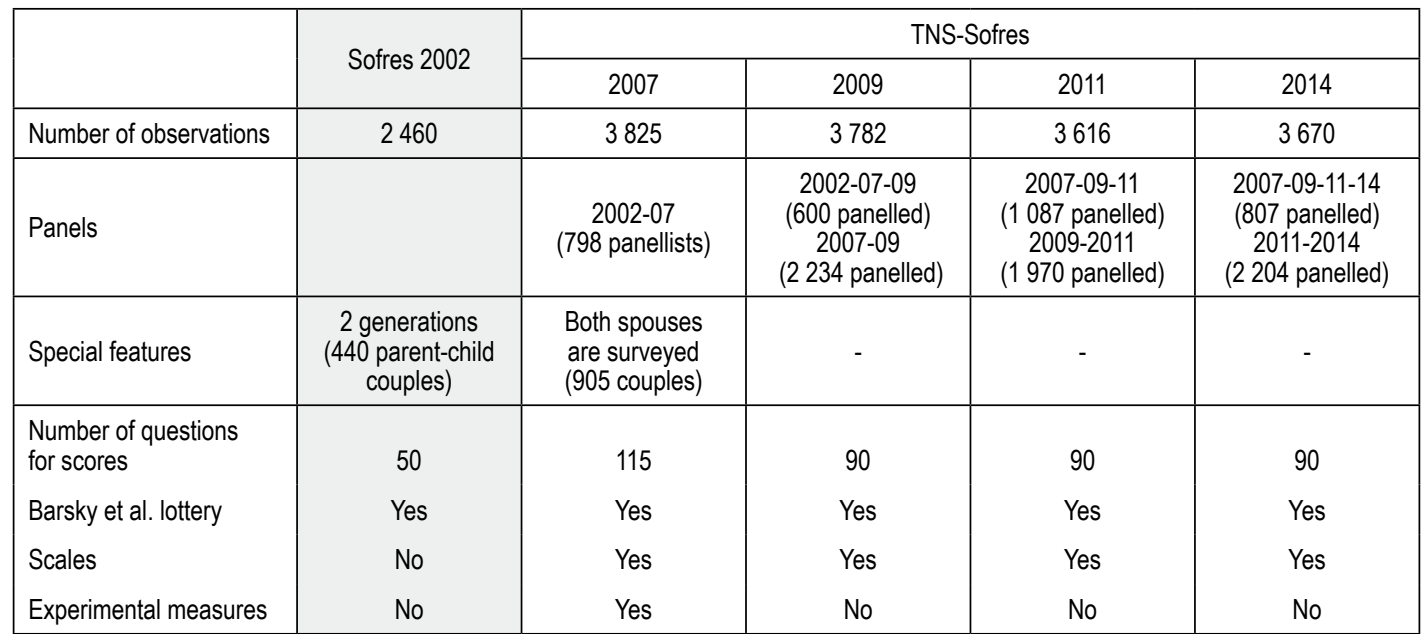

Figure

Pater survey waves and change in CAC40

Table B

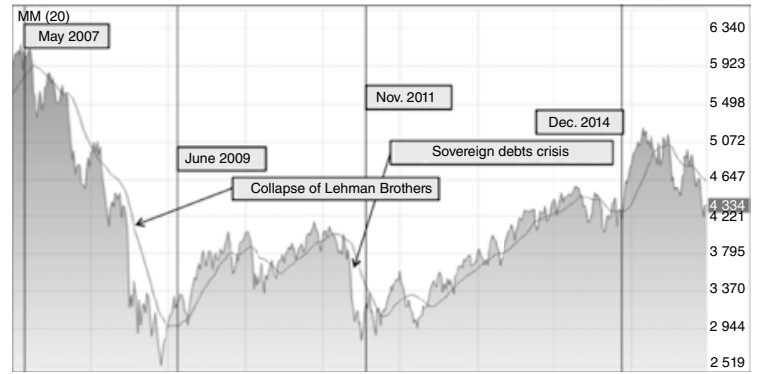

Questions from Pater survey on expectations about the labour and stock markets

C33 In 5 years' time, do you think that your household's income (salary, event described will occur The total sum of the responses in the column must be equal to 100 .

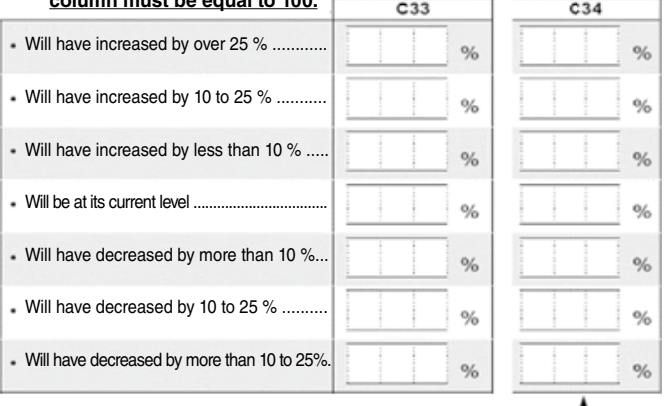

C34 In 5 years' time, again, do you think that the Stock Market. For each item, rate the likelihood in plain text, from 1 to 100, that the event described will occur. The total sum of the responses in the
column must be equal to 100 .

C35 In your opinion, in 5 years' time, in the event of an increase, what will be the maximum decrease (in percentage terms) in... Write down the percentage in
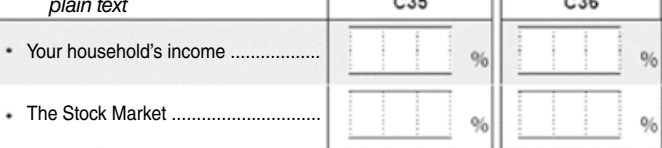

C36 In your opinion, in 5 years' time, in the event of a decrease, 
four waves: $27.8 \%$ in 2007 , vs. only $14.8 \%$ in $2014(-47 \%)$.

Moreover, when these 807 households studied from 2007 to 2014 are interviewed regarding their overall financial investment strategies, it emerges that a growing percentage of them believe that "all savings should be placed into safe investments", even though a slight decrease can be seen in the last wave: $59 \%$ in 2007 , $66 \%$ in $2009,72 \%$ in 2011 , and $67 \%$ in 2014 (Figure II). The same can be seen across broader samples: even though, in terms of behaviours, no recent increase can be seen in demand for risky assets (see Figure I), the French are said to now appear more inclined toward turning to the stock market than at the peak of the crisis. It should be noted that this type of question is used by some authors to measure individuals' risk aversion (Guiso et al., 2014, Malmendier \& Nagel, 2011), probably wrongly, as it mixes up preference and behaviour.

Through these two statistics, our data thus show that, while the French may have deserted the stock market since the 2008 crisis, they are however now not hostile to returning to it. If they are not, actually, returning, the challenge lies in understanding the reasons. A tendency toward caution can also be seen in the respondents' answers to a more evasive question: "Would you say that, since the financial crisis, you have become more careful, less careful, or have not changed?" In 2009, while half of households reported that their behaviour had not changed, the other half (48\%), made up primarily of the most underprivileged, also most exposed to the crisis classes (low level of education, low income), reported being more cautious. In 2011 and in 2014, the cautious group grew into the majority.

Beyond these broad changes, it is important to see that households did not respond in a uniform manner to the context of crisis, in particular along the distribution of income or wealth. Nonetheless, one observation remains indisputable: in the face of the crisis, the French became more cautious in their financial behaviour, looking to place their savings in safer investments and concurrently limit their risky investments; and this change appears to have been even starker after the sovereign debt crisis of Summer 2011 than following the macro-economic shock created by the collapse of Lehman Brothers in September 2008.

\section{... but expectations during the crisis showing growing pessimism only up to 2011}

In addition to estimating preferences, the 2007 to 2014 waves of the Pater survey aimed to measure household expectations on the return and risk connected with financial assets, as well as those on their future earned income. One method for measuring expectations on earned income or pensions involves offering the respondent the chance to assign probability to different possible levels of variation over the

Figure I

Percentage of shareholders (direct or indirect) in 2007, 2009, 2011 and 2014

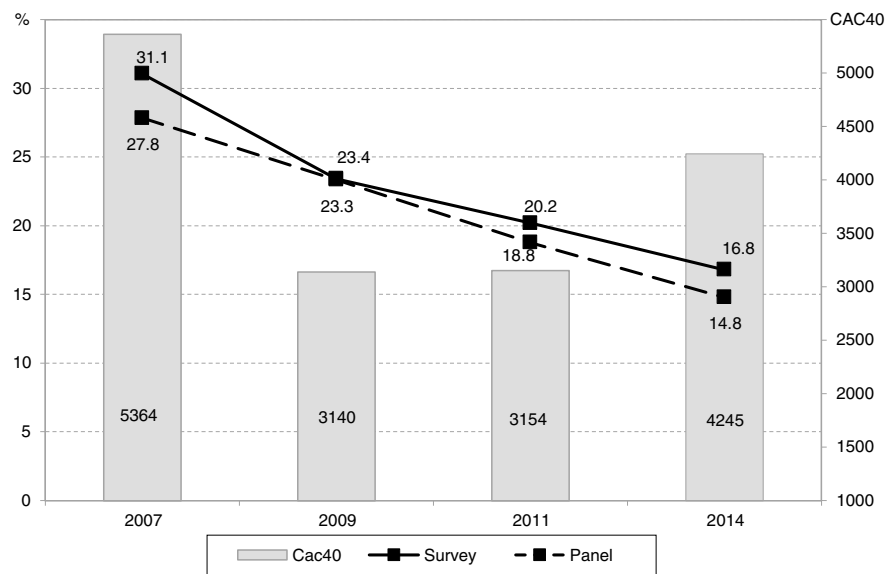

Reading note: In $2011,20.2 \%$ of households in the survey owned shares directly or via mutual funds. This percentage amounted to $18.8 \%$ in the panel sample. As at the survey date, the CAC 40 was at 3,154 points.

Coverage: Total sample representative of the French population and panelled population having responded to all 4 waves of the survey (807 individuals)

Source: Pater surveys 2007, 2009, 2011 and 2014. 
Figure II

When it comes to financial investments, what is your preference? $(\%)$

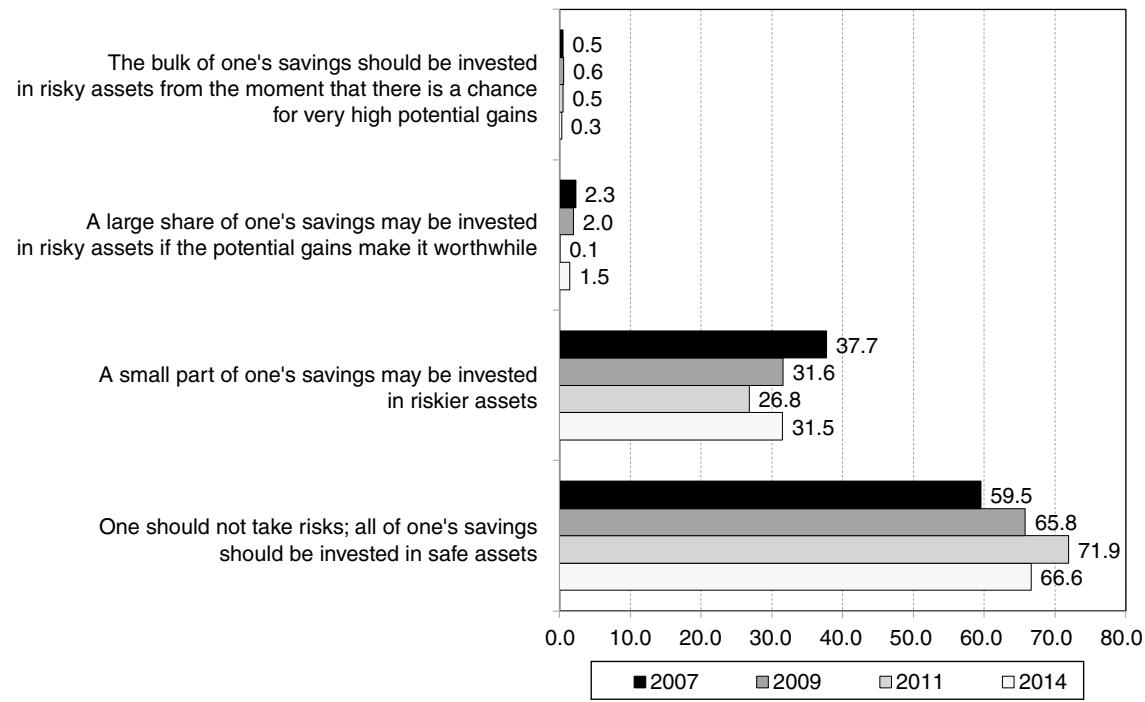

Reading note: In $2007,59.5 \%$ of those having responded to all three successive waves of the Pater Survey gave preference to "putting all their savings in safe investments". The percentages amounted respectively to $65.8 \%$ in $2009,71.9 \%$ in 2011 , and $66.6 \%$ in 2014 .

Coverage: Panelled population responding to all 4 survey waves.

Source: Pater surveys 2007, 2009, 2011 and 2014.

next five years, upward (from 0 to $10 \%$, from 10 to $25 \%$, above $25 \%$ ), downward (same brackets), or unchanged (see Box 1, Table 1). This makes it possible to reconstruct the breakdown in anticipated changes in income and thus deduce the related mean and variance. ${ }^{5}$ The same method has also been used to measure stock market expectations. ${ }^{6}$ Asked in the same manner in 2007, 2009, 2011 and 2014, these questions make it possible to approach the impact of the crisis on the same savers over two, three, or even all four waves. As these questions are relatively complex, they are also subject to an unusually high non-response rate: in each wave, as for the individuals in the panel, only slightly more than half of those surveyed responded adequately. Descriptive analysis, however, shows that the characteristics of respondents and non-respondents are not markedly different (although the respondents appear to have more time available to answer the questionnaire).
Figure III shows the resulting values for an expected average 5-year return on the stock market, on four dates, for the total population and various sub-populations. One of the first conclusions matches up with those of studies on other countries, whether American or other, already cited: low expected return, even in 2007, is not entirely compatible with rational expectations. ${ }^{7}$ Secondly, it can be observed that, in the overall population, the average expected return sharply declines over the period: from $5.5 \%$ in 2007 to $1.4 \%$ in 2014 , after a drop of 2 points in $2009(3.5 \%)$ and 3.5 points in $2011(0 \%)$. The same trend can be seen in the expectations of the respondents to the four waves: approximately $5.0 \%$ in 2007 , $4.5 \%$ in $2009,0 \%$ in 2001 and $1 \%$ in 2014 .

In summary, even though a slight return to "optimism" can be noted in 2014, the French were, at the height of the crisis, very pessimistic on the stock market prospects, and this

7. When surveyed about past changes in the CAC 40, Pater respondents (2007) underestimated on average the performance of the market index over the previous five years, placing it at $12 \%$ compared to the actual $20 \%$ observed (see Arrondel et al., 2016). It can be noted nonetheless that the modal value (over one-fourth of the sample) matches reality, thus attesting to a certain level of information in the population surveyed. 
could explain the fact that they have moved (even farther) away from it. ${ }^{8}$

Lower income expectancy, fainter return prospects on equities and an expected increase in risks impacting the labour market (see footnote 8): this increased pessimism on the part of households since the crisis, though it does seem to have faded in 2014, appears to have stirred them, consistently with the portfolio choice theory, to turn away from risky investments, either as a result of the supposed smaller attractiveness of these investments, or to mitigate the overall risks which they faced (risk substitution). The downward adjustment in professional and equity expectations could thus in large part explain the more cautious behaviour of households since the crisis, even more pronounced after 2009. What about preferences, though?

\section{The traditional measures find risk aversion on the increase from 2007 to 2011}

Three measures of risk preference will be analysed now. The first is based on hypothetical lottery choices regarding individual permanent

8. Likewise, household expectations regarding future changes in labor income have been adjusted downward: overall, the French anticipated that their income would increase on average by more than $3 \%$ in 2007, and by $2 \%$ in 2009, but foresaw stagnation in 2011 and 2014. income (Barsky et al., 1997). The individual is offered a variety of work contracts in place of the existent one, generating life cycle income $R$ : for instance, a contract under which the individual has a likelihood of $1 / 2$ to earn 2 times more income $R$ and likelihood of $1 / 2$ to earn only $2 / 3$ of $R$. This method makes it possible to classify individuals into four categories, from the least to the most risk-tolerant (Sahm, 2008). The second measure is based on self-reported levels of aversion/appetite on a scale of 0 to 10 (Likert scale, see Dohmen et al., 2011). The third and final measure, which is more original, consists of "profiling" individuals using our scoring method.

Table 1 shows the population breakdown (balanced panel) by response to the lottery question. According to this measure, the same individuals became, on average, more risk averse after the crisis, at least up to the end of 2011: $51.8 \%$ rejected the two contracts in 2007 , as compared to over $60 \%$ in 2009 and 2011, and still $59 \%$ in 2014; conversely, $7.9 \%$ were ready to accept both contracts in 2007 compared to $5.4 \%$ in $2009,3.5 \%$ in 2011 and $6.0 \%$ in 2014 . This lottery thus shows that individuals possibly became more risk averse at the time of the 2008 and 2011 market shocks, but would have become slightly more tolerant since then (at least back to the 2009 levels).

Figure III

Average expected return (over the next 5 years) on the stock market in 2007, 2009, 2011 and 2014

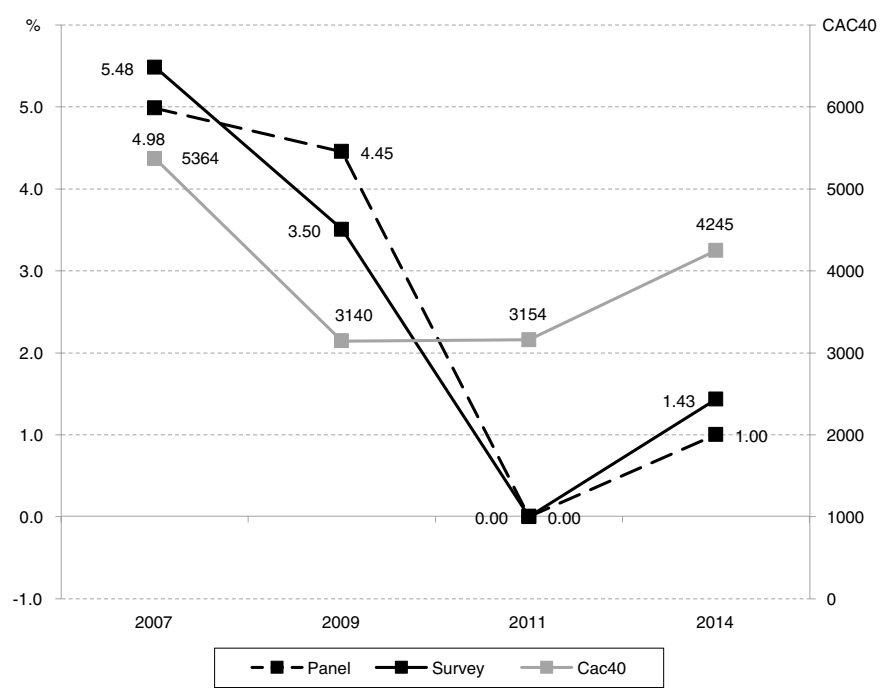

Reading note: In 2009 , households expected average return of $4.45 \%$ on the financial market $(3.50 \%$ amongst households having responded to all 4 waves of the survey). As at the survey date, the CAC 40 was at 3,140 points.

Coverage: Total sample representative of the French population and panelled population having responded to all 4 waves of the survey.

Source: Pater surveys 2007, 2009, 2011 and 2014. 
Figure IV illustrates individuals' average self-reported positioning on the Likert scales, as regards risk preference ("+" indicating greater risk tolerance). As to global risk, it can be seen that the 2008 and 2011 shocks had a negative effect on risk tolerance (4.6 in 2007 compared to 4.3 in 2009 and 4.0 in 2011) as was the case with the lottery. There too, however, a slight turnaround can be seen in 2014 (4.1), though relatively smaller than with the lottery (still below the 2009 levels).

If these preferences are measured as in the Barsky et al. lottery (1997) or using a Likert scale, it can be assumed that individuals became more tolerant to risk during the crisis, at least up to 2011, but then regained, in 2014- to varying extents-some of their lost appetite for risk.

These measures present some major flaws, however, as has been pointed out in the literature (Arrondel and Masson, 2014). Lotteries on professional decision-making, for instance, lack constancy over time, and the responses provided by a single individual can vary significantly and inconsistently from one survey to the next (as can be seen in American data as well as in our own data); they depend on

Table 1

Distribution according to Barsky et al. lottery (1997) in 2007, 2009, 2011 and 2014

\begin{tabular}{|c|c|c|c|c|}
\cline { 2 - 5 } \multicolumn{1}{c|}{} & \multicolumn{2}{c|}{ Contract A rejected } & \multicolumn{2}{c|}{ Contract A accepted } \\
\cline { 2 - 5 } \multicolumn{1}{c|}{} & $\begin{array}{c}\text { Contract C } \\
\text { rejected }\end{array}$ & $\begin{array}{c}\text { Contract C } \\
\text { accepted }\end{array}$ & $\begin{array}{c}\text { Contract B } \\
\text { rejected }\end{array}$ & $\begin{array}{c}\text { Contract B } \\
\text { accepted }\end{array}$ \\
\hline Relative risk aversion: $\gamma$ & $3.76=<\gamma$ & $2=<\gamma<3.76$ & $1=<\gamma<2$ & $\gamma<1$ \\
\hline 2007 & 51.8 & 22.3 & 18.0 & 7.9 \\
\hline 2009 & 60.2 & 20.0 & 14.4 & 5.4 \\
\hline 2011 & 63.4 & 21.2 & 11.9 & 3.5 \\
\hline 2014 & 59.0 & 21.7 & 13.3 & 6.0 \\
\hline
\end{tabular}

Reading note: $63.4 \%$ of individuals rejected both contracts in 2011 (and thus showed high aversion to risk y) while only $6 \%$ accepted both contracts (respectively low risk aversion).

Coverage: Panelled population responding to all 4 survey waves.

Source: Pater surveys 2007, 2009, 2011 and 2014.

Figure IV

Likert scale distributions in 2007, 2009, 2011 and 2014

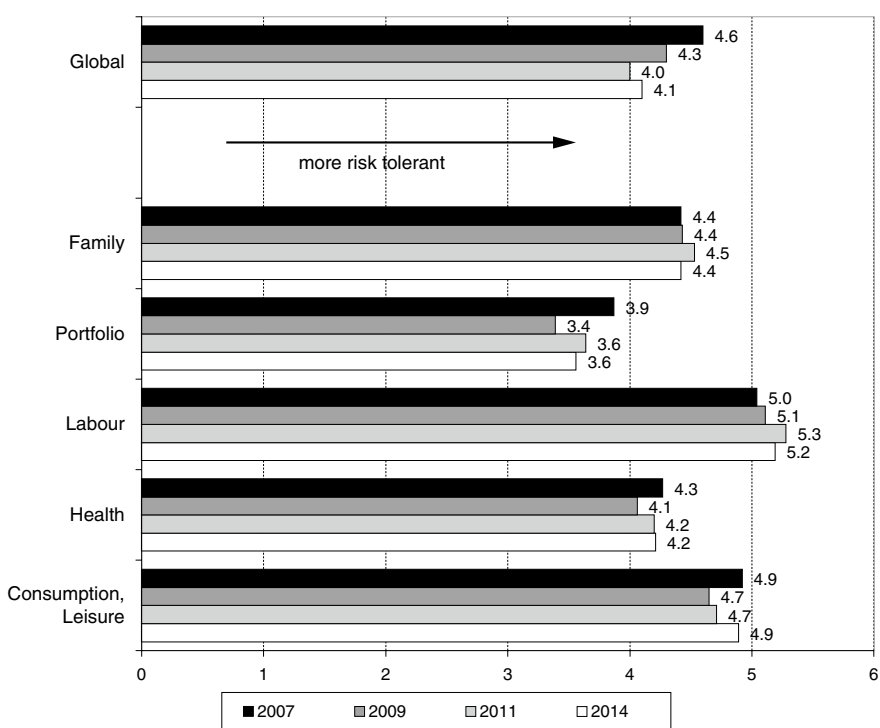

Reading note: In 2007, the average response on overall risk scale (between 0 and 10) amounted to 4.6. The average was 4.0 in 2011: Respondents thus became more risk-averse.

Coverage: Balanced panel (807 individuals)

Source: Pater surveys 2007, 2009, 2011 and 2014. 
the respondent's exposure to risk, in particular with regard to their personal wealth; they furthermore lead to biased results, insofar as they are more accessible to individuals with greater financial literacy. The Likert scales, meanwhile, show well-known anchoring biases (around the central value, 5); they too are unstable from survey to survey, but to a lesser degree than lottery choices.

Two inter-related questions thus arise: do measures as sensitive to the economic environment as these truly reflect an intrinsic risk preference? Is their evolution over time not merely reflect households' greater exposure (to unemployment risk, for instance), or does it echo too closely changes in job- or equity-related expectations, expectations that were increasingly pessimistic up to 2011? More specifically, two interpretation hypotheses can be offered for the above results:

Hypothesis H1: despite their limitations, the usual measures attest to an overall increase in risk aversion after the 2008 and 2011 shocks, the magnitude of which cannot however be assessed with precision; savers fell victim to "trauma" after each shock, and even more so after the second. The preference stability assumption of the standard theory is thus rejected, and the influence of "emotions" on tastes must be taken into account, at least where major macro-economic shocks are concerned.

Hypothesis $\mathrm{H} 2$ : the obvious biases hampering the usual measures are such that their results are not robust, as they can be the result of parasite variations in exposure to risks or in expectations. They do not make it possible to discard the hypothesis of globally stable preferences after each shock.

Unless available measures at close intervals before and after each shock, making it possible to eliminate "noise", it is hardly possible to opt in favour of one or the other of these hypotheses. A more satisfying, but also more costly measure of risk preferences will enable us to do so.

\section{The scoring method finds attitudes to risk insentitive to the crisis}

Our original approach to measuring savings' preferences, in particular with regard to risk, is based on a scoring procedure devised and improved for the past fifteen years, with each wave of the Pater survey (Arrondel and Masson,
2014). Using an extensive questionnaire that spans multiple areas of life, the idea is to build, for each respondent, summary and consistent ordinal measurements -qualitative "scores"that assess their general attitude toward risk and uncertainty, as well as their time preference in a life-cycle perspective, their degree of impatience in the short term and their degree of altruism toward their children (a more detailed presentation is provided in Box 2). Where risk is concerned in particular, the score based on sixty identical questions in each wave, does not present the flaws of the usual measures (lottery choice or self-reported Likert scale) and offers statistical properties that are far superior and much more robust from one wave to the next (see Box 2).

\section{Age and period effects}

What does the risk aversion score tell us about changes in preferences during the crisis? The score histograms sketched out two by two, first for the sub-population of households interviewed before and after the collapse of Lehman Brothers (in 2007 and 2009), and secondly for those surveyed before and after the sovereign debt crises in 2009 and 2011, and lastly for respondents to waves in 2011 and 2014, overlap almost perfectly, with nearly the same average on two successive dates, and they are actually not statistically different (figure V-A): the Kolmogorov-Smirnov test shows 0.0299 in 2007-2009 (significance threshold: 0.269), 0.0163 for 2009-2011 (threshold: 0.956) and 0.0372 for 2011-2014 (threshold: 0.102). The first two graphs in Figure V-A are particularly enlightening and tend to plead in favour of Hypothesis H2: the score proves broadly insensitive to both crisis-related shocks, suggesting an absence of period effects on risk preferences; the change recorded with the usual risk aversion measures would then be an artefact due to parasite phenomena.

As concerns the 2007 and 2014 histograms regarding the respondents to the four waves (figure V-B), the Kolmogorov-Smirnov test ( 0.0720 with a significance threshold at 0.033$)$ shows, however, a significant shift to the right, i.e., growing risk aversion over the period: taking into account the previous results, it is likely that this change reflects nothing more than an age effect, the individuals being 7 years older. All of the surveys, French (including Pater) or foreign, show that risk aversion, regardless of the measure adopted, is increasingly a function 
of age with cross-section data; and this consensus on a negative age effect on risk tolerance extends to the smaller number of longitudinal studies (see Sahm, 2012, for instance). ${ }^{9}$

9. The identification of an age effect in connection with risk aversion on an interval limited to 7 years does not give rise to any particular problems. The same cannot be said over a longer period, including with our risk aversion score, as an anonymous commenter pointed out: some questions necessarily refer to "situations that are quite different", depending on whether the respondent is young or old: "Involvement [current or past] in extreme sports, opinion on marriage, the virtues of social monogamy, the desire to live a longer life, etc." We check that removing the most contentious questions did not change the substance of the most conclusions that emerged (except for limiting score quality).
The results of the statistical analysis are supported by econometric analysis. Table 2-A shows a regression (linear model) of the determinants of the risk aversion score. This model is the same as a cross-sectional regression, but in which the four waves are stacked (and variances are "clusterized"). ${ }^{10}$ We obtain again the effects highlighted in each of the survey's waves

10. As to the variables that do not change over time, the estimation is probably robust. In contrast, for those that change over time, the estimation shows a bias that can be corrected using panel data econometrics techniques.

\section{Figure V-A}

\section{Risk score histograms in 2007, 2009, 2011 and 2014}
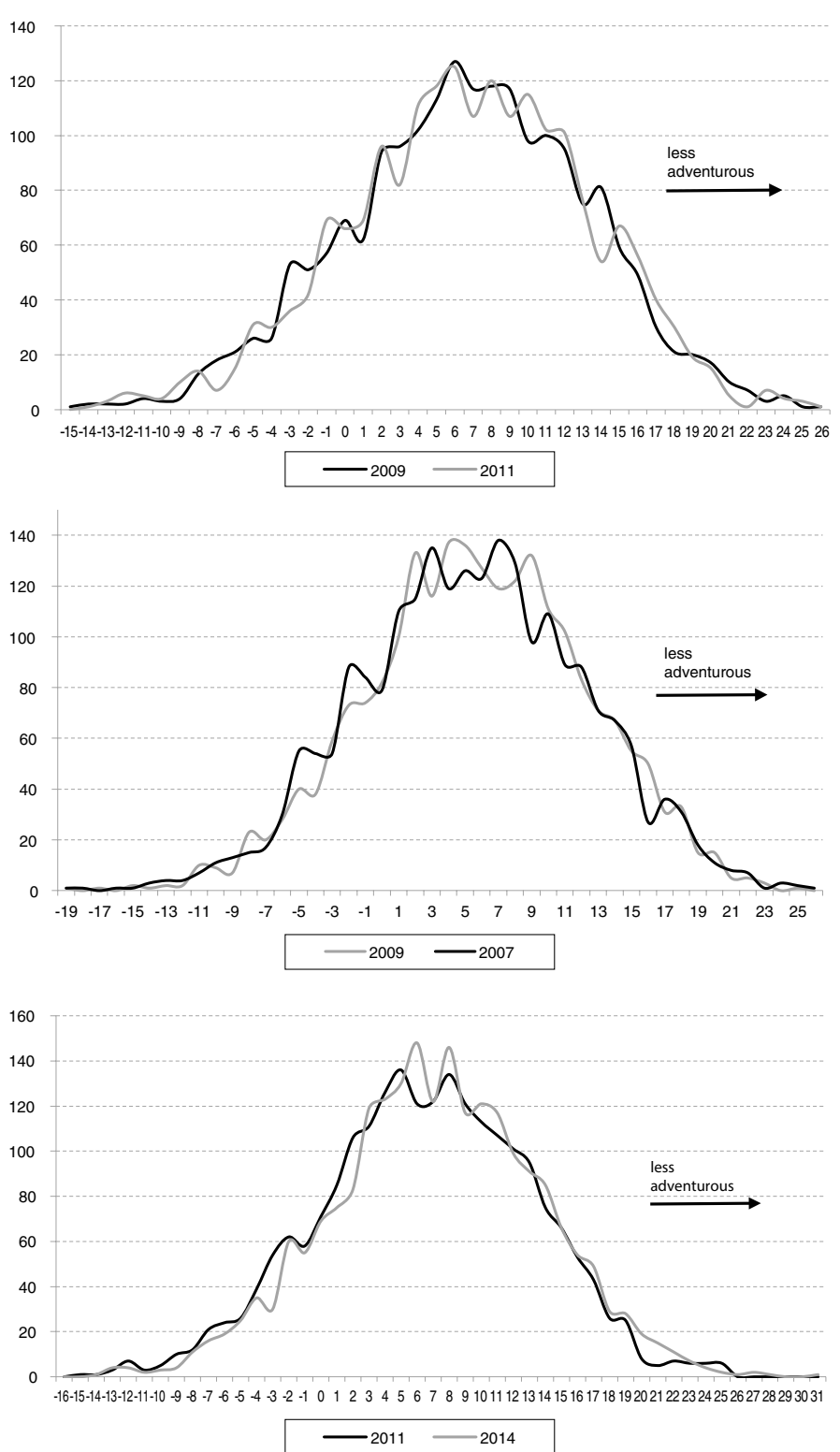

Reading note: Over 140 respondents posted a risk score of 6 in 2014. There were 120 of them in 2011.

Coverage: Panelled population responding to two successive survey waves.

Source: Pater surveys 2007, 2009, 2011 and 2014. 
Figure V-B

\section{Risk score histograms between 2007 and 2014}

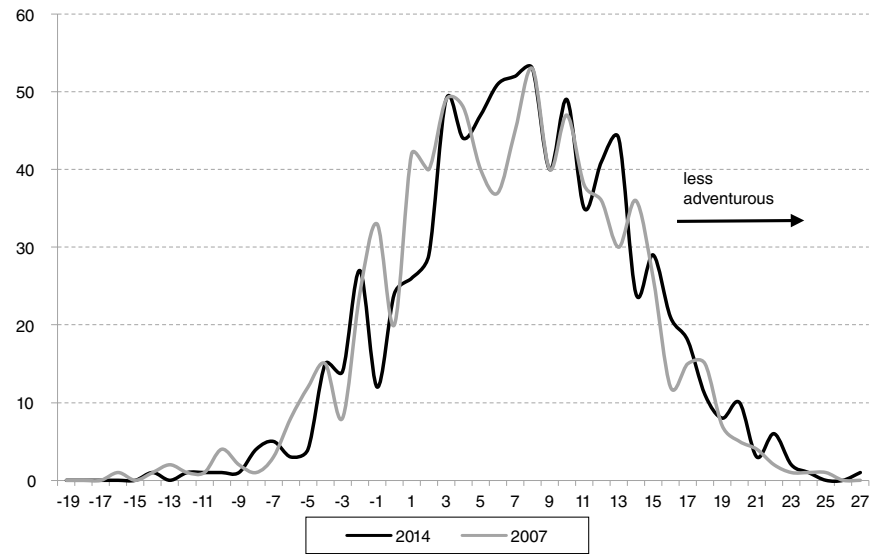

Analysis: Less than 40 respondents posted a risk score of 6 in 2007. There were 50 of them in 2014.

Coverage: Panelled population responding to all 4 survey waves.

Source: Pater surveys in 2007 and 2014.

\section{Box 2 - The scoring method}

Our method for measuring individual preferences involves devising scores to "profile" individuals, based on their taste for risk, the way they approach the future, and their degree of parental altruism, that is, the three components of savings and wealth accumulation models (see Arrondel \& Masson, 2014, for a detailed presentation). Tested and developed with data from the Insee's Household Wealth survey 1998, then the 2002 TNSSofres survey, this method was repeated for the last four waves Pater in 2007, 2009, 2011 and 2014.

These summary and ordinal scores are computed on the basis of over one hundred questions covering a wide range of economic and social areas, such as consumption, leisure, investments, work, family, health, retirement, etc. These questions are often concrete or related to everyday life or plans, and are relatively easy to answer; others are more abstract, and pertain to responses to fictional scenarios or lottery choices. On the basis of these questions, the aim was to build, for each respondent, consistent relative indicators or "scores" on preferences or attitudes in the four fields identified in the theoretical literature: risk or uncertainty; preference for the present in the long term; preference for the present in the short-term, or "impatience"; and family altruism. The scores are meant as aggregate measures, qualitative and ordinal metrics, assumed representative of the responses provided by the respondent to a range of questions. Some examples of these questions have been listed below:

- attitude with regard to risk: "Do you take an umbrella with you when the weather looks iffy?" or "Do you park your vehicle illegally?";

- lottery choices, consumer practices: "Do you ever go to live performances randomly, even if it might mean setting yourself up for disappointment?":

- opinions: "Do you agree with the assertion that 'marriage is an insurance policy"?" or: "Are you sensitive to the debate over current issues in health (AIDS, contaminated blood, etc.)?"
- reference question to identify future depreciation rate: "Due to an unexpected increase in workload, your employer asks you to postpone your week on holiday by one year, offering in exchange to grant you $X$ additional days of leave. Do you agree?"

The scores used in this article are based on 58 questions to measure attitudes toward risk and 30 on preference for the present.

This raises the issue of how many different scores should be placed within a given area of preference, in particular that of uncertainty. (Non-standard) theory refers to several parameters of risk preference: risk aversion, ambiguity and loss; "temperance" (in managing multiple risks); "pessimism" or "optimism" (in assessing subjective change in probabilities), etc. Experimental data, meanwhile, would rather show that subjects do not respond in the same way to small and large risks and that the responses given to questions on anecdotal choices or on vital decisions cannot be considered on the same plane. Lastly, attitudes with regard to risk are likely to vary from one domain of life to another: after all, paragliding and tax evasion are both risky activities but have little in common.

\section{Computation of the scores}

The first stage consists of assigning a priori the questions asked to one of the four areas of preference listed earlier. Some overlapping is difficult to avoid, for instance, as regards the distinction between the short-term and the long-term, and even more so regarding the fact that the future is both uncertain and remote from the present. Consequently, items such as "Would you find it worth the effort, if it enabled you to live a few years longer, to forego what you deem are the pleasures in life?", and "In order to avoid health problems, do you watch your weight or your diet, do you engage in sports, etc.?", were assigned to both risk preference and time preference. 
Box 2 (suite)

No question isolated from the others is adequate for measuring a given preference parameter. If a question is focused on theory (a lottery, for instance), it can appear too abstract and generate a lot of "noise" (in particular from one wave to the next). In contrast, the way in which responses to lifestyle questions is interpreted inevitably raises issues, due to context effects and irrelevant factors: a risk-tolerant individual might consequently, as a civic act, never "park in no-parking zone". The underlying idea is thus that only the "average" of all responses would have meaning, provided that the aggregation makes it possible to generally do away with parasite dimensions (bias, context effect, endogeneity, etc.)

The statistical method thus consists, as a second stage, of encoding responses, in general into three modalities; for instance, for attitudes toward risk: risk-loving $=-1$; neutral $=0$; risk-averse $=+1$; then adding up the resulting "ratings" for each individual. The score is the sum of all the ratings, limited to only those items which, ex post, turn out to have formed a statistically consistent set.

As regards the number of scores to be incorporated into each area of preferences, data have the last say. Yet statistical analysis gives rise to a remarkable outcome: out of the four waves of Pater, we were able to test that a single score is always enough to characterise, ordinally, the respondent's attitudes toward risk and uncertainty: it then has to be interpreted as a mix between the individual's degree of risk aversion or prudence, as well as his/her aversion to loss or ambiguity. We were also able to see that time preference, impatience in the short term and altruism toward one's children can each be characterised by a single, representative, score in each Pater sample. This constancy in results attests the robustness of the scoring method we chose.

The fact that this method was able to be fully-reproduced in different Pater survey waves made it possible to test its robustness on other crucial points: the number of questions needed to build scores, the factors explaining the scores, time auto-correlations of scores; the explanatory power of financial behaviours. The results of these tests are detailed in online complement $\mathrm{C} 2$.

In addition, the scores are far better correlated from one survey to the next than the standard indicators. Lastly, in all waves of the Pater survey, it can be seen that:

- The characteristics of households have greater explanatory power: over the stacked sample, for instance, the pseudo R2 of the qualitative regression is $7.0 \%$ using the score method, (see Table 2-A), vs. 1.4\% with the lottery and $0.9 \%$ with the scale.

- The explanatory power of the scores on various risky behaviours (demand for risky assets, entrepreneurship, etc.) is always higher with the risk scoring method than for scales of the same kind, lottery nonetheless sometimes doing just as well, though it subsequently requires to be corrected for endogenity biases (Sahm, 2012).

- The scores' specific effects on financial behaviours and portfolio choices are far greater, quantitatively, but also highly comparable from one wave to the next. To take only one example: an increase in the score's standard deviation (less risk tolerance) decreases the probability of share ownership by a comparable percentage, around $3 \%$.

Scores prove excellent instruments for other preference measurement. In a wealth regression estimated using the instrumental variables method, the score of risk aversion used as an instrument for other measures is shown to have very high predictive power and that it is statistically exogenous. This tends to support the idea that scores are a collection of "natural" instruments in the approach to individual preferences.
(Arrondel \& Masson, 2014): risk tolerance is highest amongst young singles, men, children of self-employed (except sons or daughters of farmers, who are more risk-averse), and when the children no longer live at home. This regression also shows risk aversion to be increasing in the most recent waves: overall, the population appears to be less tolerant to risk. If we operate from the assumption that the risk score depends only on age, this overall change results solely from composition effects: population ageing, new young households more risk-averse than the previous generations, etc. However, to verify such a hypothesis, age and period effects would have to be separated, when the two variables are perfectly correlated.
In attempting to respond to this question, we will compare the characteristics of the risk score, risk scale and lottery distributions as a function of the observation period and the individuals' age (Table 2-B). These regressions are based only on those individuals having responded to all four surveys (balanced panel) and simply pile up the observations. This selection makes it possible for us to econometrically test whether the crisis has had an effect on any of these three preference indicators. The first specification distinguishes between the observations only by the date of observation: a significant increase can be seen in risk aversion during the crisis until 2011 for each measure. In the second specification age is introduced as an additional variable: 
here, it can be noted that, where the score is concerned, the onset of the crisis does not appear to have any influence on preferences once taken into account the ageing of the panelled individuals, whereas for other measures (scale or lottery), the impact of the shock remains, growing until 2011, then receding in 2014.

Did savers become more risk-averse during the crisis? The answer to this question depends on preference measurement. While the scale and lottery methods appear to show growing risk aversion of individuals (up to 2011), risk scores, in contrast, indicate that savers have not "changed" overall: adjusting for age effects, they are on average just as risk-tolerant as they were prior to the crisis, no more, no less; this holds true as much after the September 2008 shock as in the longer term, after that of Summer 2011 or in 2014. Considering the score-method's superior reliability, this conclusion appears the most relevant to us.

\section{Why is financial behaviour more cautious since the crisis?}

Since the crisis, households have displayed behaviours testifying to lesser appetite for risky assets, generally stable risk preferences,

Tableau 2-A

Risk score determinants (linear model)

\begin{tabular}{|c|c|c|}
\hline & \multicolumn{2}{|c|}{ OLS } \\
\hline Variables & Coef. & Robust- $t$ \\
\hline \multicolumn{3}{|l|}{ Wave (ref : 2007) } \\
\hline 2009 & 0.4317 & 3.96 \\
\hline 2011 & 0.8321 & 6.43 \\
\hline 2014 & 0.7951 & 4.51 \\
\hline Age & 0.1334 & 30.81 \\
\hline \multicolumn{3}{|l|}{ Income (ref : Q1) } \\
\hline Q2 & 1.0122 & 4.47 \\
\hline Q3 & 1.0270 & 4.47 \\
\hline Q4 & 1.1237 & 4.52 \\
\hline No response & 1.7273 & 6.33 \\
\hline Sex: female & 2.5938 & 18.69 \\
\hline Married & 1.6539 & 10.75 \\
\hline \multicolumn{3}{|l|}{ Social background (ref.: Employee) } \\
\hline Farmer & 0.7909 & 3.81 \\
\hline Self-employed & -0.5226 & -2.55 \\
\hline Liberal profession & -0.1893 & -0.49 \\
\hline \multicolumn{3}{|l|}{ Education (ref.: < Baccalaureate) } \\
\hline Baccalaureate & -0.0270 & -0.16 \\
\hline$>$ Baccalaureate & -0.1378 & -0.84 \\
\hline \multicolumn{3}{|l|}{ Number of children } \\
\hline Living in the family home & -0.0788 & -1.24 \\
\hline Independent (living on their own) & -0.2199 & -3.47 \\
\hline Constant & -7.6059 & -20.02 \\
\hline $\mathrm{N}$ (observations) & & \\
\hline $\mathrm{n}$ (individuals) & & \\
\hline R2 & & \\
\hline
\end{tabular}

Note: Stacked samples (14,895 observations and 8,435 individuals).

Reading note: Age has a statistically significant positive effect (Robust $t>1.96$ ) on the risk score: the older one is, the more risk-averse. Robust $t$ : clustered variances.

Coverage: Population without missing data in regressions.

Source: Pater surveys, 2007, 2009, 2011 and 2014 waves. 
available resources relatively unaffected by the crisis in the majority of cases -but also increasingly gloomy expectations on earned income and risky financial assets. A priori, the source of behavioural change thus presumably lies in individuals' perception of the economic environment rather than in their psyche. The estimation of equation (3) allows to test this hypothesis. The choice of the dependent variable proves a delicate one. The amounts invested in shares, for instance, are impaired by serious measurement errors (all the more troublesome when used in differences) and can reflect capital gains or losses. The focus here will thus be only on changes in share ownership, whether direct or indirect. Demand (Equation 2) is estimated using simple probit models ("clusterizing" variances) on the stacked sample, and probit models with random effects on the sample restricted to individuals having responded prior to the crisis and at least once afterwards, and on the balanced panel (the estimation results are shown in Table C3-1 of online Complement C3). Changes in stock ownership are estimated by linear models in difference.

Another variable, possibly better suited and available in the four waves from 2007 to 2014 , pertains to the financial investment strategy depicted in Figure II, in four modalities (only one response possible), from "put all your savings into safe investments" up to "put most of your savings into risky investments, but which can result in high returns". With respect to shareholding, this variable further offers the benefit of identifying household intentions on risky investments, these intentions sometimes differing from actual behaviours for reasons which remain to be highlighted. The responses to this question are first analysed based with an ordered probit model over the stacked samples and with a linear random effects model over samples restricted to those responding to at least two waves (including that of 2007) and over the balanced sample (Table C3-2 of online Complement C3). Table 4 shows the determinants of behavioural change based on a linear model in difference.

We check (equation (2)) that the risk and time preference scores have the expected significant effects: the less risk tolerant an individual is, the less that individual will be attracted to risky assets, whether in terms of share owning or intention to hold shares (see tables in online Complement C2); the more far-sighted a person, the more she turns to this type of asset. The total wealth level also has a significant positive effect, while the amount of earned income impacts only share ownership, and expected future risk on that income has no effect on shares owned, but is thought to play out in a relatively positive way on the propensity to take portfolio risks (in contrast to a "temperance" strategy). Age and level of education are also major positive factors, linked with the level of financial information, in explaining risk taking; likewise, having or having had shareholding parents positively influences individuals' likelihood to own shares or intent to purchase shares themselves. As for the expectation variables, the expected shares return has

Table 2-B

Risk score determinants (linear models) OLS

\begin{tabular}{|l|cccc|cccc|cccc|}
\hline & \multicolumn{5}{|c|}{ Score } & \multicolumn{4}{|c|}{ Scale } & \multicolumn{4}{c|}{ Lottery } \\
\hline Variables & Coef. & $\mathrm{t}\left(^{*}\right)$ & Coef. & $\mathrm{t}\left(^{*}\right)$ & Coef. & $\mathrm{t}\left(^{*}\right)$ & Coef. & $\mathrm{t}\left(^{*}\right)$ & Coef. & $\mathrm{t}\left(^{*}\right)$ & Coef. & $\mathrm{t}\left(^{*}\right)$ \\
\hline 2009 wave & 0.199 & 1.24 & -0.101 & -0.61 & -0.407 & -4.23 & -0.452 & -4.67 & 0.165 & 4.05 & 0.165 & 3.98 \\
2011 wave & 0.405 & 2.35 & -0.131 & -0.70 & -0.674 & -7.15 & -0.757 & -7.84 & 0.253 & 6.17 & 0.252 & 5.99 \\
2014 wave & 0.808 & 4.37 & -0.148 & -0.68 & -0.559 & -5.69 & -0.706 & -6.76 & 0.146 & 3.39 & 0.144 & 3.20 \\
Age & & & 0.118 & 8.12 & & & 0.0184 & 4.17 & & & 0.001 & 0.11 \\
Constant & 6.228 & 26.76 & -0.127 & -0.15 & 5.661 & 65.72 & 4.669 & 18.49 & 3.186 & 85.87 & 3.175 & 32.28 \\
\hline $\mathrm{N}$ (Obs.) & 3,168 & & 3,168 & & 3,084 & & 3,084 & & 2,884 & & 2,884 \\
$\mathrm{n}$ (Indiv.) & 792 & & 792 & & 771 & & 771 & & 721 & & 721 \\
R2 & 0.002 & & 0.063 & & 0.014 & & 0.026 & & 0.010 & & 0.010 \\
\hline
\end{tabular}

Notes: Stacked samples (balanced). *: Robust t, clustered variances.

Reading notes: Risk score regressions show that the significance of dummies relative to each wave disappears when age is taken into account in contrast to what happens with scale and lottery.

Coverage: Panelled population responding to all 4 survey waves.

Source: Pater survey, 2007, 2009, 2011 and 2014 waves. 
a (significant) positive effect, the significance of which is often comparable to that of the risk score (while volatility has no effect). ${ }^{11}$ Lastly, it is ensured that portfolio risk taking decrease significantly with the observation period.

The analysis of behavioural change (Equation 3) is based on a linear model in difference (Tables 3 and 4). The estimates show that variations in the risk score do not have any effect. As for variations in financial expectations, only those regarding the expected share return have a significant and positive effect (Table 4). It should also be noted that those individuals who reported to have been affected by the crisis

11. This outcome is consistent with those observed in demand for equities: Arrondel, Calvo and Tas (2016) show, for instance, on the Pater 2007 data, that the latter depends statistically on expected stock market returns: the decision to own or not own shares correlates positively with the expected risk premium, thus eliminating in effect those who estimate it to be negative. more (or as much as) the average have, in some cases, sold their shares (see Table 3 ).

In summary, the trend in French savers' financial behaviours during the crisis, reflected in a lesser propensity for risk-taking, cannot be explained by an overall change in preferences as measured by the scores. The differences affecting available resources (or the expected earned income) do not have any greater explanatory power. Only those households considering that they had been "more affected by the crisis than on average" sold their shares more than the others. In contrast, individual variations in the anticipations on expected stock returns do have a significant effect: the greater pessimism shown by the French population on the whole in this area would then be the main cause (on the demand side) behind the lesser overall appetite for risky assets since the crisis.

Table 3

Determinants of share ownership (in difference)

\begin{tabular}{|c|c|c|c|c|}
\hline Variables & Coef. & Robust $t$ & Coef. & Robust $t$ \\
\hline Risk-aversion score (in difference) & -0.002 & -1.12 & -0.0022 & -1.05 \\
\hline Time preference score for present (in difference) & -0.002 & -0.73 & -0.0020 & -0.72 \\
\hline Expected stock market return (in difference) & 0.092 & 1.67 & 0.0886 & 1.66 \\
\hline Expected variance in future income (in difference) & -0.193 & -0.41 & -0.2232 & -0.47 \\
\hline \multicolumn{5}{|l|}{ Wave (ref : 2014) } \\
\hline 2009 & -0.021 & -1.06 & -0.0321 & -1.44 \\
\hline 2011 & 0.023 & 0.94 & 0.0152 & 0.57 \\
\hline Age & -0.001 & -2.99 & -0.0019 & -3.28 \\
\hline \multicolumn{5}{|l|}{ Affected by the crisis (ref.: more than the average) } \\
\hline Less than the average & & & 0.0780 & 2.39 \\
\hline As much as the average & & & 0.0776 & 2.38 \\
\hline No response & & & -0.0927 & -0.69 \\
\hline \multicolumn{5}{|l|}{ Education (ref.: < Baccalaureate) } \\
\hline Baccalaureate & & & -0.0063 & -0.36 \\
\hline$>$ Baccalaureate & & & 0.0064 & 0.4 \\
\hline Married & & & 0.0255 & 1.69 \\
\hline \multicolumn{5}{|l|}{ Number of children } \\
\hline living with parents & & & 0.0018 & 0.25 \\
\hline Independent (living on their own) & & & -0.0094 & -1.11 \\
\hline Constant & 0.037 & 1.11 & -0.0184 & -0.40 \\
\hline Number of observations & 2,023 & & 2,023 & \\
\hline Number of individuals & 1,231 & & 1,231 & \\
\hline
\end{tabular}

Note: Robust t: clustered variances.

Reading note: The expected stock market return has a statistically significant positive effect of $10 \%$ ( $t=1.67$ in the first model) on demand for shares Coverage: Sample of individuals having responded in 2007 and at least one time thereafter.

Source: Pater surveys 2007, 2009, 2011 and 2014 
Table 4

Propensity for risk-taking (in difference)

\begin{tabular}{|c|c|c|c|c|}
\hline Variables & Coef. & $t$ & Coef. & $t$ \\
\hline Risk-aversion score (in difference) & -0.006 & -1.55 & -0.006 & -1.53 \\
\hline Time preference score for present (in difference) & -0.001 & -0.24 & 0.000 & -0.07 \\
\hline Expected stock market return (in difference) & 0.293 & 2.88 & 0.295 & 2.92 \\
\hline Expected variance in future income (in difference) & 0.457 & 0.48 & 0.444 & 0.47 \\
\hline \multicolumn{5}{|l|}{ Wave (ref : 2014) } \\
\hline 2009 & -0.080 & -4.53 & -0.107 & -1.41 \\
\hline 2011 & -0.019 & -0.79 & -0.041 & -0.51 \\
\hline 2014 & 0.028 & 1.13 & 0.001 & 0.01 \\
\hline Age & & & 0.000 & -0.17 \\
\hline \multicolumn{5}{|l|}{ Affected by the crisis (ref.: more than the average) } \\
\hline Less than the average & & & 0.049 & 0.76 \\
\hline As much as the average & & & 0.049 & 0.75 \\
\hline No response & & & 0.112 & 1.57 \\
\hline \multicolumn{5}{|l|}{ Education (ref.: < Baccalaureate) } \\
\hline Baccalaureate & & & -0.012 & -0.42 \\
\hline > Baccalaureate & & & 0.033 & 1.39 \\
\hline Married & & & -0.007 & -0.32 \\
\hline \multicolumn{5}{|l|}{ Number of children } \\
\hline living with parents & & & -0.010 & -0.95 \\
\hline Independent (living on their own) & & & -0.006 & -0.44 \\
\hline Number of observations & 1,892 & & 1,892 & \\
\hline Number of individuals & 1,164 & & 1,164 & \\
\hline
\end{tabular}

Note: Robust t: clustered variances.

Reading note: The expected stock market return has a statistically significant positive effect of $10 \%$ ( $t=2.88$ in the first model) propensity for risk-taking in portfolio choices.

Coverage: Sample of individuals having responded in 2007 and at least one time thereafter.

Source: Pater survey, 2007, 2009, 2011 and 2014 waves.

With four waves from 2007 to 2014 and a strong panel-based dimension, the Pater data now offer the possibility to analyse numerous questions regarding savings, wealth and inequalities, providing a useful supplement, with more subjective and qualitative aspects of financial behaviours, to the information from the Insee's Wealth surveys. Like other sources, the Pater data highlight the lesser appetite of the French to take risks in their savings or their portfolio decisions during the crisis. Our article shows that this change in behaviours is not due to a change in the preferences of the savers we followed during the crisis: these preferences are thought to have remained -age effect aside- statistically stable since June 2007. The lesser willingness to take risks is thought to be the result, above all, of increasingly gloomy expectations regarding the (expected) return from financial assets.

The stability of risk preferences over time, observed on the basis of our scores goes against the conclusions of other empirical studies measuring preferences using other methods (Likert scale, lottery, qualitative questions). By refuting the psychological impact of the current crisis on investor tastes, this result should be credited to standard saver theory rather than to behavioural economics, which establishes a parallel between emotions -sometimes even "fear"- and preferences. These results, however, call for further investigations in a variety of directions.

A new wave of the Pater panel would likely round out our study on multiple points. First of all, it would enable us to determine whether 
the French are gradually returning to the stock market (demand for equities decreased at least up to March 2016) as certain indicators appeared to show in 2014, as well as why this delay might occur. It would secondly enable more robust statistical checks, over a less limited sample. As regards preferences, the aim will be to analyse changes in the distribution of risk aversion within an ageing population, the new generations of which will be those of the
"Great Recession". Secondly, we have highlighted one last puzzle, as regards individual shareholders' demand for equities: if, in actuality, if French savers have indeed deserted the Stock Market since 2008, the curve of their investment intentions on the stock market turned around in 2014. What remains to be understood then is why households' financial intentions and behaviours are now diverging and for how long.

\section{BIBLIOGRAPHY}

Arrondel, L. \& Masson, A. (2014). Mesurer les préférences des épargnants : comment et pourquoi (en temps de crise) ? Economie et Statistique, 467-468, 5-49. https://www.insee.fr/fr/statistiques/fichier/1377942/ ES467A.pdf

Arrondel, L. \& Masson, A. (2015). Could French and Eurozone Savers Invest More in Risky Assets? Bankers, Markets \& Investors, 138, 4-16.

Arrondel, L., Bartiloro, L., Fessler, P., Lindner P., Mathä, T. Y., Rampazzi, C., Savignac, F., Schmidt, T., Schürz, M. \& Vermeulen, P. (2016). How do households allocate their assets? - Stylized facts from the Eurosystem Household Finance and Consumption Survey. International Journal of Central Banking, 12(2), 129-220.

Arrondel, L., Calvo Pardo, H. \& Tas, D. (2016). Subjective Stock Market Expectations, Information and Stock Market Participation: Evidence from France. Summer Institute Economic Fluctuations and Growth, NBER Cambridge MA, 16-20 juillet 2012. http://www.economics.soton.ac.uk/staff/calvo/ documents/SubjectiveExpectations-16012012.pdf

Arrow, K. J. (1965). Aspect of the Theory of Risk Bearing. Helsinki, Yrjö Johnson Lectures.

Barberis, N., Huang, M. \& Thaler, R. (2006). Individual Preferences, Monetary Gambles, and Stock Market Participation: A Case for Narrow Framing. American Economic Review, 96(4), 1069-1090.

Barsky, R. B., Kimball, M. S., Juster, F. T. \& Shapiro, M.D. (1997). Preference Parameters and Behavioral Heterogeneity: An Experimental Approach in the Health and Retirement Survey. Quarterly Journal of Economics, 112 (2), 537-580.
Benartzi, S. (2001). Excessive extrapolation and the allocation of $401(\mathrm{k})$ accounts to company stock. Journal of Finance, 56, 1747-1764.

Bossaerts, P., Ghirardato, P., Guarnaschelli, S. \& Zame, W. (2010). Ambiguity in asset markets: theory and experiment. Review of Financial Studies, 23(4), 1325-1359.

Chanel, O., Lyk-Jensen, S., Massoni, S. \& Vergnaud, J.C. (2014). Stabilité des préférences dans le risque après une expérience à fort impact psychologique. mimeo.

Chuang, Y. \& Schechter, L. (2015). Stability of Social, Risk, and Time Preferences Over Multiple Years. Journal of Development Economics, 117, 151-170.

Cohn, A., Engelmann, J., Fehr, E. \& Maréchal, M. A. (2015). Evidence for countercyclical risk-aversion: An experiment with financial professionals. American Economic Review, 105 (2), 860-885.

Dohmen, T., Lehmann, H. \& Pignatti, N. (2016). Time-varying individual risk attitudes over the Great Recession: A comparison of Germany and Ukraine. Journal of Comparative Economics, 44(1), 182-200.

Dominitz, J. \& Manski, C. (2007). Expected Equity Returns and Portfolio Choice: Evidence from the Health and Retirement Study. Journal of the European Economic Association, 5(2-3), 369-379.

Dominitz, J. \& Manski, C. (2011). Measuring and Interpreting Expectations of Equity Returns. Journal of Applied Econometrics, 26(3), 352-370. 
Ellsberg, D. (1961). Risk, Ambiguity, and the Savage Axioms. Quarterly Journal of Economics, 75(4), 643-669.

Epstein, L. G. \& Schneider, M. (2010). Ambiguity and asset markets. Annual Review of Financial Economics, 2(1), 315-346.

French, K. R. \& Poterba, J. M. (1991). Investor diversification and international equity markets. American Economic Review, 81(2), 222-226.

Gollier, C. (2001). The Economics of Risk and Time. Cambridge: MIT Press.

Gollier, C., (2013). Édito. Les cahiers Louis Bachelier, 8, 1 .

Grinblatt, M., Keloharju, M. \& Linnainmaa, J. (2011). IQ and Stock Market Participation. The Journal of Finance, 66(6), 2121-64.

Guesnerie, R. (2010). Quelle est la responsabilité des économistes dans la crise actuelle ? La Lettre de PSE, 3, 1.

https:/www.parisschoolofeconomics.eu/fr/actualites/ roger-guesnerie-responsabilite-economistes-crise2008/

Guiso, L. \& Jappelli, T. (2005). Awareness and Stock Market Participation. Review of Finance, 9(4), 537-567.

Guiso, L. \& Jappelli, T. (2007). Information Acquisition and Portfolio Performance. Economics Working Papers ECO2007/45. Florence, European University Institute.

http://www.csef.it/WP/wp167.pdf

Guiso, L., Sapienza, P. \& Zingales, L. (2008). Trusting the stock market. The Journal of Finance, 63(6), 2557-2600.

Guiso, L., Sapienza, P. \& Zingales, L. (2014). Time varying risk aversion. NBER Working Papers $\mathrm{N}^{\circ} 19284$

http://www.nber.org/papers/w19284

Guiso, L. \& Sodini, P. (2012). Household Finance: An Emerging Field. In: Constantinides, Harris \& Stulz (Eds.), Handbook of the Economics of Finance, Volume 2, Part B, chap. 21, Elsevier.

Hall, R. E. (2010). Why Does the Economy Fall to Pieces after a Financial Crisis? Journal of Economic Perspectives, 24(4), 3-20.

Hong, H., Kubik, J. D. \& Stein, J. C. (2004). Social Interaction and Stock Market Participation. The Journal of Finance, 59(1), 137-163.
Hudomiet, P., Kézdi, G. \& Willis, R. J. (2011). Stock Market Crash and Expectations of American Households. Journal of Applied Econometrics, 26(3), 393-415.

Jouini, E., Benmansour, S. \& Napp, C. (2006). Is there a "pessimistic" bias in individual beliefs? Evidence from a simple survey. Theory and Decision, 61(4), 345-362.

Kahneman, D., (2012). Thinking, Fast and Slow. Farrar, Straus \& Giroux.

Kahneman, D. \& Tversky, A. (1979). Prospect Theory: An Analysis of Decision under Risk. Econometrica, 4752, 263-291.

King, M. \& Leape, J. (1998). Wealth and Portfolio Composition: Theory and Evidence. Journal of Public Economy, 69(2), 155-193.

Lusardi, A. (Ed.) (2009). Overcoming The Saving Slump: How to Increase the Effectiveness of Financial Education and Saving Programs. Chicago: University of Chicago Press.

Lusardi, A. \& Mitchell, O. (2014). The Economic Importance of Financial Literacy: Theory and Evidence. Journal of the Economic Literature, 52 (1), $5-44$.

Malmendier, U. \& Nagel, A. (2011). Depression Babies: Do Macroeconomic Experiences Affect Risk-Taking? Quarterly Journal of Economics, 126(1), 373-416.

Merton, R. C. (1971). Optimal Consumption and Portfolio Rules in a Continuous Time Model. Journal of Economic Theory, 3(4), 373-413.

Modigliani, F. (1986). Life Cycle, Individual Thrift and the Wealth of Nations. American Economic Review, 76(3), 297-313.

Necker, S. \& Ziegelmeyer, M. (2016). Household risk taking after the financial crisis. Quarterly Review of Economics and Finance, 59, 141-160.

Sahm, C. (2012). How much does risk tolerance change? Quarterly Journal of Finance, 8(2), $141-160$.

Stigler, G. J. \& Becker, G. S. (1977). De Gustibus Non est Disputandum. American Economic Review, 67(2), 76-90.

Stiglitz, J. E. (2011). Rethinking Macroeconomics: What Went Wrong and How to Fix it. Journal of the European Economic Association, 9(4), 594-645. 
Tracol, K. (2016). Le rôle des anticipations dans le comportement des épargnants. Thèse EHESS, Paris.

Tversky, A. \& Kahneman, D. (1974). Judgment under Uncertainty: Heuristics and Biases. Science, 185(4157), 1124-1131.

Van Rooij, M., Lusardi, A. \& Alessie, R. (2011). Financial Literacy and Stock Market Participation. Journal of Financial Economics, 101(2), 449-472.
Vissing-Jorgensen, A. (2003). Perspectives on behavioral finance: does 'irrationality' disappear with wealth? Evidence from expectations and actions. In: Gertler \& Rogoff (Eds), NBER Macroeconomics Annual, 139-194. Cambridge, MA: MIT Press. www.nber.org/chapters/c11443.pdf

Weber, M., Weber, E. \& Nosi, A. (2013). Who Takes Risks When et Why: Determinants of Changes in Investor Risk Taking. Review of Finance, 17(3), 847-883. 
